\section{An Introduction to Analytical Geometry}

By A. Robson. Vol. 2. Pp. viii+215. (Cambridge : At the University Press, 1947.) 10s. $6 d$.

$\mathrm{T}$ HIS is a continuation of an earlier volume published in 1940. The most original part of Vol. 2 is Chapter 19, on general geometry. This, with its references to $G_{5}, G_{6}$ and $G_{7}$, is at first sight difficult to understand, but becomes clear and very interesting if we refer back to Chapter 8 of Vol. 1. The leading idea, expanded from a suggestion of the late Prof. G. H. Hardy, is that what is usually called analytical geometry of two dimensions is not one subject, but several. The simplest kind, called $G_{2}$, corresponds closely to Euclidean geometry $G_{1} . G_{3}$ is similar to $G_{2}$, but regards a 'point' as merely a term for an ordered pair of real numbers $x$ and $y$. In $G_{4}$ these numbers are no longer real, but complex. In $G_{5}$ we keep the pair real, and supplement them by a third real number $z$, introduced to make the equations homogeneous. Points at which $z=0$ are called points of infinity. $G_{6}$ has triplets of complex numbers, thus combining the advantages of $G_{4}$ and $G_{5}$. In both $G_{5}$ and $G_{6}$ the points of infinity and the line on which they lie are exceptional. In $G_{7}$ all points and lines are on an equal footing. Theorems which are true in one kind of geometry may be untrue or even absurd in another. This discussion clears up the paradoxes which used to puzzle us concerning lines at right angles to themselves and separate points the distance apart of which is zero. However, the schoolboy, for whom the author professes to write, may not find this part of the book easy.

The other chapters of Vol. 2 deal respectively with homography, involution, ranges on a conic, systems of conics, reciprocation, the general cartesian conic, foci and confocals, normals and evolutes, and special homogeneous co-ordinates. The amount of space given to trilinear and areal co-ordinates is much less than in the older books, in which these were often applied, at great length, to metrical problems for which they were unsuited. There is a good stock of examples, of varying degrees of difficulty. At first sight there appears to be an ugly misprint on p. 14, but on reference to the beginning of Vol. 1 it will be discovered that "wo" is not a misprint, but an abbreviation for "with respect to".

Teachers should examine the book carefully, for the freshness of the outlook will throw new light on several parts of what used to be looked upon as a stereotyped subject.

H. T. H. Praggio

\section{A Bibliographic Classification}

Extended by Systematic Auxiliary Schedules for Composite Specification and Notation. By Henry Evelyn Bliss. Vol. 2: Classes $H-K$; the Human Sciences. Pp. vii +344. (New York : H. W. Wilson Company, 1947.) 7.50 dollars.

THIS volume sets forth the specifications and 1 schedules in Bliss's classification for anthropology and the medical sciences, psychology (including psychiatry), education and sociology, including ethnology, folk-lore, ethnography and human geography. The expansions for the medical sciences have been compiled with the assistance of Mr. C. C. Barnard, and those for physiology, medicine and surgery have more recently been revised by Dr. R. B. Singer. The classification for psychology has been compiled in collaboration with Dr. C. M. Louttit, while the schedules for sociology, social ethnology and folk-lore have been revised by Miss Beverly Stamm. Although Bliss's classification is little known outside the ranks of librarians and bibliographers, the scholarly introduction to this volume will be read with appreciation by many who are interested in the more comprehensive human sciences. Its interest is not so much in the explanation of the principles of the classification itself as in the discussion of the various complications involved, including questions of terminology, where an admirable and forceful plea for greater precision is advanced. Particularly in what he has to say on sociology, Dr. Bliss makes a valuable contribution to greater pre. cision in the use of terms and in the relation of concepts and ideas which should be welcomed by all serious students in this field, independent of whether or not they adopt his classification as a convenient working tool.

R. B.

The Graduate School Research and Publications Edited with a Foreword by Prof. Edgar W. Knight and Agatha Boyd Adams. (University of North Carolina: Sesquicentennial Publications.) Pp. viii + 461. (Chapel H.ill, N.C. : University of North Carolina Press ; London: Oxford University Press, 1946.) 22s. net.

7 HIS further volume in the imposing series issued. in celebration of the sesquicentenary of the University of North Carolina records the development of the graduate school and describes the resources for research which the University possesses in its library, research laboratories, its permanent institutes, its learned societies and clubs and its various learned journals and allied periodicals. The library resources have already been described more fully in an earlier volume in this series, but the present volume also includes an account of the activities of the University press. Apart from Prof. Pierson's discussion of the future of the graduate school and the relations between teaching and research, in which that twin function of a university is firmly upheld, these parts of the volume are chiefly of historical interest. The greater part of the volume, however, is occupied by a comprehensive list of the individual publications of the faculty, the administrative officers and other members of the University staff from the founding of the University, arranged alphabetically by name and classified according to the various administrative offices and faculties, departments or schools.

Industrial Research, 1947

Advisory Editor: Dr. Percy Dunsheath. Pp. 535. (London and New York: Todd Reference Books, Ltd., 1947.) 25s. net.

1 HE second edition of this book represents a considerable advance on the first. The extraneous and redundant material has been largely eliminated, and a readable and adequate survey of progress in industrial research in Britain during $1946-47$ by Dr. B. J. A. Bard replaces the hotch-potch of essays included in the first edition. The statements from Government and public bodies and from private organisations are properly classified, as is the information on university laboratories and the research laboratories of private firms. The sections on officially appointed committees and reports and on books, periodicals and films have also been improved, and the latter list, limited to books published in 1946 or in preparation in 1947, is much more useful than the earlier list. The report from the Industrial Research Committee of the Federation of British Industries on industrial research in technical colleges is given 